\title{
Heart and Brain Interaction of Psychiatric Illness: A Review Focused on Heart Rate Variability, Cognitive Function, and Quantitative Electroencephalography
}

\author{
Wookyoung Jung ${ }^{1}$, Kuk-In Jang ${ }^{2,3}$, Seung-Hwan Lee ${ }^{4,5}$ \\ ${ }^{1}$ Department of Psychology, Keimyung University, Daegu, ${ }^{2}$ Department of Biomedicine and Health Sciences, College of Medicine, The Catholic \\ University of Korea, ${ }^{3}$ Institute of Biomedical Industry, The Catholic University of Korea, Seoul, ${ }^{4}$ Department of Psychiatry, ${ }^{5}$ Clinical Emotion \\ and Cognition Research Laboratory, Ilsan Paik Hospital, Inje University College of Medicine, Goyang, Korea
}

\begin{abstract}
Heart rate variability (HRV) reflects beat-to-beat variability in the heart rate due to the dynamic interplay of the sympathetic and parasympathetic nervous systems. HRV is considered an index of the functional status of the autonomic nervous system. A decrease in HRV is thus observed in individuals with autonomic dysfunction. Abnormal HRV has been reported in a range of mental disorders. In this review, we give an overview of HRV in patients with major depressive disorder (MDD), schizophrenia, and posttraumatic stress disorder (PTSD), one of whose core symptoms is cognitive dysfunction. The association between HRV and cognitive function is highlighted in this review. This review consists of three main sections. In the first section, we examine how HRV in patients with MDD, schizophrenia, and PTSD is characterized, and how it is different when compared to that in healthy controls. In the second section, beyond the heart itself, we discuss the intimate connection between the heart and the brain, focusing on how HRV interacts with quantitative electroencephalography (qEEG) in the context of physiological changes in the sleep cycle. Lastly, we finish the review with the examination of the association between HRV and cognitive function. The overall findings indicate that the reduction in HRV is one of main manifestations in MDD, schizophrenia, and PTSD, and also more generally HRV is closely linked to the change in qEEG and also to individual differences in cognitive performance.
\end{abstract}

KEY WORDS: Heart rate variability; Major depressive disorder; Schizophrenia; Posttraumatic stress disorder; Electroencephalography; Cognition.

\section{INTRODUCTION}

Heart rate variability (HRV), which is a measure of beat-to-beat variability in heart rate (HR) over time as assessed using electrocardiography, has been considered a convenient, noninvasive indicator of autonomic nervous system (ANS) activity [1]. The ANS is composed of two distinct systems: the sympathetic nervous system (SNS) and the parasympathetic nervous system (PNS). Each system is dominant under certain conditions. The SNS pre-

Received: August 9, 2018/ Revised: November 30, 2018 Accepted: December 19, 2018

Address for correspondence: Seung-Hwan Lee Department of Psychiatry, Ilsan Paik Hospital, Inje University College of Medicine, Juhwa-ro 170, Ilsanseo-gu, Goyang 10380, Korea

E-mail: Ishpss@paik.ac.kr

ORCID: https://orcid.org/0000-0003-0305-3709 dominates during emergency "fight-or-flight" reactions or exercise, while the PNS predominates during quiet, resting conditions [2]. The two systems work together and always strive to be in balance.

An optimal level of HRV within an organism reflects healthy function and an inherent self-regulatory capacity, adaptability, or resilience [3]. Excessive instability, such as arrhythmias or nervous system dysfunction, is detrimental to efficient physiological functioning, while insufficient variation reflects age-related system depletion, chronic stress, pathology, or inadequate functioning in various levels of self-regulatory control systems $[4,5]$.

$H R V$ generally means the variability of $R-R$ intervals. The analysis of HRV comprises measurements of time-domain, frequency-domain, and nonlinear complexity. The time-domain analysis, which is the simplest way to analyze $H R V$ as being calculated directly from the raw $R-R$

(ㄷ) This is an Open-Access article distributed under the terms of the Creative Commons Attribution Non-Commercial License (http://creativecommons.org/licenses/by-nc/4.0) which permits unrestricted non-commercial use, distribution, and reproduction in any medium, provided the original work is properly cited. 
interval time series, is separated into two categories: beat-to-beat intervals derived directly from the intervals themselves, and intervals derived from the differences between normal $R-R$ intervals [6]. We present the standard parameters of $H R V$ with the most frequently used parameters of the time domain (Table 1): parameters of the first category include SDNN, SDANN and SD, and the second category includes RMSSD and pNN50. SDNN is a global index of HRV, and reflects the standard deviation of the normal $\mathrm{R}-\mathrm{R}$ intervals ( $\mathrm{N}-\mathrm{N}$ intervals). SDANN reflects the standard deviation of all $R-R$ intervals in successive five-minute epochs, and SD reflects the standard deviation of the differences between successive $\mathrm{R}-\mathrm{R}$ intervals, and also reflects the day and night changes of HRV. While SDNN reflects the total variability during the recording period, SD reflects the short-term variability [7]. RMSSD reflects the square root of the mean sum of squares of successive $\mathrm{R}-\mathrm{R}$ differences, and pNN50 reflects the percentage of successive $R-R$ intervals that differ by more than $50 \mathrm{~ms}$. RMSSD is sensitive to high-frequency heart period fluctuations in the respiratory frequency range and has been used as an index of vagal cardiac control.

The frequency domain analysis measures the periodic oscillations of the HR signal composing different frequencies and amplitudes, and provides information on the amount of their relative variance or power in the heart's sinus rhythm [6]. In the frequency-domain analysis, power spectral density (PSD) of the $R-R$ intervals is measured. Methods for measuring the PSD estimate can be divided into two categories: a nonparametric method such as fast Fourier transform and a parametric method such as autoregressive models [7]. The analysis of the PSD is performed by the powers and peak frequencies for different frequency bands, which include very low frequency (VLF, $0.005-0.04 \mathrm{~Hz}$ ), low frequency (LF, 0.04 $-0.15 \mathrm{~Hz}$ ), and high frequency (HF, $0.15-0.4 \mathrm{~Hz})$. The most frequently used frequency domain parameters are presented in the Table 1 . The total power of $R-R$ interval variability is the total variance and corresponds to the sum of the three spectral bands, VLF, LF, and HF $[8,9]$. The VLF component was proposed as a major determinant of physical activity [6] and might reflect long period rhythms. The LF component is modulated by sympathetic activity of $H R$. The HF component is generally defined as a marker of vagal (parasympathetic) modulation. The LF/HF ratio reflects the global sympatho-vagal balance.

For the non-linear complexity measure, approximate entropy (ApEn) measures the regularity and complexity of a time series. The ApEn was designed for brief time series in which some noise may be present and makes no assumptions regarding underlying system dynamics [10]. Applied to HRV data, large ApEn values indicate low pre-

Table 1. Parameters of heart rate variability (HRV)

\begin{tabular}{|c|c|c|c|c|}
\hline Type & Parameter & Unit & Description & Comment \\
\hline \multirow[t]{5}{*}{ Time domain } & SDNN & $\mathrm{ms}$ & $\begin{array}{l}\text { Standard deviation of the normal } \mathrm{R}-\mathrm{R} \\
\text { intervals }(\mathrm{N}-\mathrm{N} \text { intervals })\end{array}$ & \\
\hline & SDANN & $\mathrm{ms}$ & $\begin{array}{l}\text { Standard deviation of } \mathrm{R}-\mathrm{R} \text { intervals in } \\
\text { successive five-minute epochs }\end{array}$ & \\
\hline & SD (or SDSD) & $\mathrm{ms}$ & $\begin{array}{l}\text { Standard deviation of the differences between } \\
\text { successive } R-R \text { intervals }\end{array}$ & \\
\hline & RMSSD & $\mathrm{ms}$ & $\begin{array}{l}\text { Square root of the mean sum of squares of } \\
\text { successive } R-R \text { differences }\end{array}$ & \\
\hline & pNN50 & $\%$ & $\begin{array}{l}\text { Percentage of successive } \mathrm{R}-\mathrm{R} \text { intervals } \\
\text { differing more than } 50 \mathrm{~ms}\end{array}$ & \\
\hline \multirow[t]{5}{*}{$\begin{array}{l}\text { Frequency } \\
\text { domain }\end{array}$} & Total power & $\mathrm{ms}^{2}$ & $\begin{array}{l}\text { Total variance and corresponds to the sum of } \\
\text { the three spectral bands, LF, HF and VLF }\end{array}$ & \\
\hline & VLF & $\mathrm{ms}^{2}$ & $\begin{array}{l}\text { Power of very low-frequency range } \\
(0.005-0.04 \mathrm{~Hz})\end{array}$ & $\begin{array}{l}\text { A major determinant of physical activity and } \\
\text { might reflect long period rhythms }\end{array}$ \\
\hline & LF & $\mathrm{ms}^{2}$ & Power of low-frequency range $(0.04-0.15 \mathrm{~Hz})$ & Modulated by sympathetic activity of heart rate \\
\hline & $\mathrm{HF}$ & $\mathrm{ms}^{2}$ & Power of high-frequency range $(0.15-0.4 \mathrm{~Hz})$ & A marker of vagal modulation \\
\hline & $\mathrm{LF} / \mathrm{HF}$ & $\mathrm{ms}^{2}$ & Ratio of LF to HF & Reflects the global sympatho-vagal balance \\
\hline $\begin{array}{l}\text { Non-linear } \\
\text { complexity }\end{array}$ & \multicolumn{2}{|c|}{ ApEn (approximate entropy) } & $\begin{array}{l}\text { Measures the regularity and complexity of a } \\
\text { time series. }\end{array}$ & $\begin{array}{l}\text { Large ApEn values indicate low predictability } \\
\text { of fluctuations in successive } \mathrm{R}-\mathrm{R} \text { intervals, } \\
\text { and small ApEn values mean that the signal is } \\
\text { regular and predictable }\end{array}$ \\
\hline
\end{tabular}


Table 2. Main findings of HRV analysis in groups of patients with MDD, schizophrenia, and PTSD

\begin{tabular}{|c|c|c|}
\hline $\begin{array}{l}\text { Types of psychiatric } \\
\text { disorder }\end{array}$ & Main finding & Reference \\
\hline \multirow[t]{4}{*}{ MDD } & Patients with depression showed reduced resting-state HF-HRV. & $\begin{array}{l}1,50,51 \\
53-57\end{array}$ \\
\hline & $\begin{array}{l}\text { Patients with more severe depression were likely to have lower HF-HRV than those with less severe depression } \\
\text { (only for adult patients). }\end{array}$ & $46,50,52$ \\
\hline & $\begin{array}{l}\text { The use of TCAs significantly reduced HRV but other antidepressants including SSRIs, mirtazapine, and } \\
\text { nefazodone had no significant impact on HRV. }\end{array}$ & 50 \\
\hline & $\begin{array}{l}\text { The use of antidepressants including TCA, SNRI, and SSRI considerably decreased HRV (when measured basal } \\
\text { RSA). }\end{array}$ & $64-66$ \\
\hline \multirow[t]{4}{*}{ Schizophrenia } & $\begin{array}{l}\text { HF-HRV was significantly reduced in patients with schizophrenia relative to healthy controls, while LF-HRV } \\
\text { is not significantly different between patients with schizophrenia and healthy controls. }\end{array}$ & $60,67,71$ \\
\hline & $\begin{array}{l}\text { The severity of psychotic symptoms, and especially cognitive/disorganization symptoms was reported to have } \\
\text { significant negative correlations with SDNN and RMSSD. }\end{array}$ & $67,72-74$ \\
\hline & $\begin{array}{l}\text { The use of atypical antipsychotics, particularly clozapine, was associated with reduced HRV (without a } \\
\text { medication-free group). }\end{array}$ & $75-77$ \\
\hline & $\begin{array}{l}\text { HRV in the medication-free patients with schizophrenia was reduced relative to healthy controls, suggesting } \\
\text { that decreased vagal function is likely to be associated with the presence of schizophrenia or psychosis itself. }\end{array}$ & 78,79 \\
\hline \multirow[t]{4}{*}{ PTSD } & $\begin{array}{l}\text { HF-HRV was reduced in patients with PTSD when compared to both subjects with past trauma and healthy } \\
\text { controls (included medication-free and non-smoker subjects). }\end{array}$ & 94 \\
\hline & $\begin{array}{l}\text { Patients with more severe PTSD symptoms showed lower HF-HRV than those with less severe PTSD } \\
\text { symptoms. }\end{array}$ & 86,94 \\
\hline & Individuals with PTSD showed a significant decrease in HRV during the traumatic script. & 95 \\
\hline & $\begin{array}{l}\text { Affective (including trauma-related) cues did not differentially influence HRV responses in patients with PTSD } \\
\text { when compared to healthy controls. }\end{array}$ & $82,84,86$ \\
\hline
\end{tabular}

MDD, major depressive disorder; HF, high frequency; HRV, heart rate variability; TCA, tricyclic antidepressant; SSRI, selective serotonin reuptake inhibitor; SNRI, serotonergic noradrenergic reuptake inhibitor; RSA, respiratory sinus arrhythmia; LF, low frequency; SDNN, standard deviation of the normal $R-R$ intervals; RMSSD, square root of the mean sum of squares of successive $R-R$ differences; PTSD, posttraumatic stress disorder.

dictability of fluctuations in successive $\mathrm{R}-\mathrm{R}$ intervals [11], whereas small ApEn values indicate that the signal is regular and predictable.

This review mainly focused on the role of the HF component in HRV analysis because the interpretation of the LF component is controversial. There exists both evidence for $[12,13]$ and against a reliable marker of sympathetic activity. A review that revisited the LF as an index of sympathetic cardiac tone concluded that the HRV power spectrum, including the LF component, is mainly determined by the PNS [14]; see also a reference [15]. $\mathrm{HF}-\mathrm{HRV}$ is considered as an index of the flexibility of vagal tone and the general capacity of the ANS to respond to changes in the environment in an adaptive way $[16,17]$. It is known that a loss of flexibility in ANS function is associated with a greater risk of cardiovascular disease (CVD) $[18,19]$ and overall mortality [20-22]. Therefore, decreased HRV has been considered a risk marker for CVD. In addition to being associated with cardiac disease itself, decreased HRV has been reported to be associated with psychiatric disease. A large body of evidence indicates that decreased HRV is an important mechanism contributing to heart failure in patients with psychiatric disorders [23,24].

We aimed to overview on the impact of psychiatric disorder on HRV. In particular, we selected major depressive disorder (MDD), schizophrenia, and posttraumatic stress disorder (PTSD) for the review since we focused on cognitive dysfunction that these three groups of psychiatric disorder have in common (Table 2). Cognitive impairments limit adaptive functioning in patients with psychiatric disorders and thus are a critical treatment focus [25]. Cognitive impairments are also the indicative of dysfunctional neuronal processes $[26,27]$, which are reflected by cardiac conditions [28], as well. It is well documented that HRV and cognitive functions are closely relevant so that by reviewing the literature we expect that research on the underlying physiological and cognitive mechanisms related to HRV may help us better understand MDD, schizophrenia, and PTSD. In addition to the disorders, dementia is also known to show an autonomic dysfunction. A recent review that examined $H R V$ indexes in older peo- 
ple with dementia reported that an autonomic dysfunction was observed in all types of dementia [29]. However, we decided to focus on psychiatric disorders that can occur in more general populations such as MDD, schizophrenia, and PTSD since dementia is more common in people over the age of 65 years so that cognitive impairment would be a natural part of aging, though it can also occur in younger people.

There exists the intimate connection between the heart and the brain [30]. HRV is known to be regulated by the prefrontal cortex (PFC) [21] - brain regions involved in the regulation of ANS activity [31]. Both the PNS and SNS are mediated by cortical-subcortical pathways which involve the PFC, the anterior cingulate cortex (ACC), the insula, the hypothalamus, and the brainstem [5]. The neurovisceral integration model proposed the neutral basis for the effect of the PFC on control of HRV [21]: the PFC regulates and tonically inhibits activity in limbic systems that suppress parasympathetic activity and activate sympathetic activity. Activation of the PFC leads change to HRV such that the two branches of the ANS produces HRV. The model also posits that increased activation of the PFC inhibits the sympathoexcitatory circuit of the amygdala, which reduces sympathetic activity and parasympathetic suppression, resulting in a reduction in $\mathrm{HR}$ (as cited in the previous study [32]), whereas decreased activation of the PFC activates parasympathoinhibitory circuit, which increases sympathetic activity and parasympathetic suppression, resulting in an increase in HR. As such, we review the evidence that HRV is related to cognitive performance due to its ability to index activity in prefrontal neural structures.

$\mathrm{HRV}$ is also considered to indirectly reflect complex patterns of brain activation [33-38] and provides information on the central nervous system (CNS) functional organization and the bidirectional interaction between the CNS and the ANS [39]. Thus, by examining the association between HRV and quantitative electroencephalography (qEEG) as the index of CNS, we seek a better understanding of underlying mechanisms that convey the dynamic interdependence of the brain and the heart; among not only populations with psychiatric disorders, but also among healthy populations.

This review deals with three main topics: HRV and psychiatric disorders, HRV and qEEG, and HRV and cognitive functioning (Fig. 1). Specifically, we review the fac-

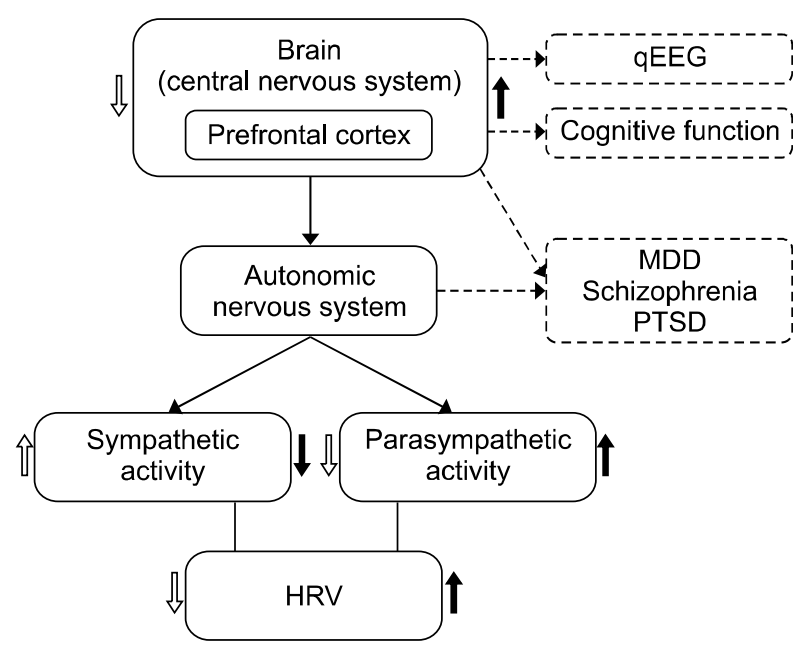

Fig. 1. Conceptual model of connection of brain (qEEG), heart (HRV), and cognitive function.

qEEG, quantitative electroencephalography; MDD, major depressive disorder; PTSD, posttraumatic stress disorder; HRV, heart rate variability.

tors associated with decreased HRV in each diagnostic group of MDD, schizophrenia, and PTSD when compared to healthy controls in the first section. The second section is a review of how HRV components interact with EEG activity in psychiatric disorder, with a focus on physiological changes in the sleep cycle. The final section is a review of how HRV is linked to individual differences in cognitive performance, and particularly executive function.

We carried out PubMed and Google Scholar searches with all relevant combinations of the following keywords: heart rate variability, HRV, autonomic nervous system, ANS, depression, major depressive disorder, MDD, schizophrenia, posttraumatic stress disorder, PTSD, qEEG, and cognitive function. We included original research reports and key reviews in the area.

\section{HRV IN PSYCHIATRIC DISORDERS}

\section{HRV in MDD}

Depression and CVD are related to each other, as 20\% to $40 \%$ of patients with CVD are reported to have depression $[40,41]$. Conversely, patients with depression are more likely to have myocardial infarction [42], even after controlling for increased body mass index, physical activity, hypertension, and hypercholesterolemia [43-45]. Depressive disorders influence ANS function by reducing parasympathetic tone and/or increasing sympathetic tone 
[46].

A large body of evidence indicates that reduced HRV in part mediates the relationship between depression and cardiac mortality [5,47-49]. However, research on HRV and depression has generally been conducted in patients who already have CVD so that the association between depression and HRV may have been overestimated. Meta-analysis by Kemp et al. [50] reported that depression without CVD is associated with reduced HRV, with relatively small effect sizes, which is consistent with another meta-analysis of the association between cardiac vagal control and depression [51]. Specifically, their findings showed that at rest or with 24-hour Holter monitor, patients with depression displayed reduced HF-HRV and reduced time domain HRV compared to healthy controls, consistent with research highlighting a strong correlation between HF-HR and RMSSD $(r=0.85)$ [1].

It is also important to consider the severity of depression when speaking of the relationship between HRV and depression. The study by Kemp et al. [50] additionally reported that patients with more severe depression are likely to have lower HF-HRV than those with less severe depression. In addition to adult populations with depression, a recent meta-analysis of children and adolescents with depression showed lower HF-HRV in clinically depressed adolescents when compared to healthy controls, whereas the association between HF-HRV and depressive symptom severity was not found, unlike in adults [52].

There are mixed results as to whether depressive mood can affect HRV. Specifically, patients with depression are reported to have reduced HRV [53-57] or no difference in HRV when compared to non-depressed controls [58-60]. These mixed results might be explained by methodological differences in measuring HRV (e.g., administration of various HRV tests at rest or with various provocation maneuvers) or by differences in the patient samples (e.g., differences in age, sex, and severity of depressive symptoms) [46]. A study that aimed to clarify such inconsistent results used more methodological strict procedures such as inclusion criteria, diagnostic procedure, statistical analysis considering age, sex, and the severity of depressive symptoms, and a large group of patients and healthy controls. The analysis of time and frequency domain HRV indices including 5-minute resting study, deep breathing test, and Valsalva test showed that after controlling for age, gender and smoking, patients with severer depressive symptoms showed a higher HR and a significantly lower modulation of cardiovagal activity compared to healthy controls, though patients with moderate symptoms did not differ from healthy controls. The study also found a negative correlation between the degree of severity of depressive symptoms and modulation of cardiovagal activity, suggesting the more severe the depressive symptoms, the lower is the cardiovagal activity. On the basis of the results, it is highly recommended that studies on association between HRV and depression consider symptom severity of depression together.

Other factor that could influence HRV in depression is antidepressants, more precisely, the class of antidepressants: tricyclic antidepressants (TCAs) and selective serotonin reuptake inhibitors (SSRIs). The review by van Zyl et al. [61] (2008) reported that TCAs were associated with declines in most measures of HRV including the time- and frequency-domains in studies (the supine condition) with short recording intervals (5 minutes), whereas no significant changes were found for 24-hour recording times. For SSRIs, short-recording studies reported an increase in only one HRV measure, SDNN, whereas 24-hour recording studies reported contradictory results such that moderate decreases or increases were found in SDNN and SDANN, and also in RMSSD $[62,63]$. The review was partially supported by Kemp et al. [50], in which the use of TCAs significantly reduced HRV but other antidepressants including SSRIs, mirtazapine, and nefazodone had no significant impact on HRV.

Meanwhile, Licht et al. [64] provided the evidence that decreased HRV in MDD was mainly due to the effects of antidepressants; HRV in MDD patients without antidepressant use did not differ from that in healthy controls. Their 2-year follow-up longitudinal study [65] measured basal respiratory sinus arrhythmia (RSA) in the supine and sitting upright positions (collapsed for the analysis) and concluded that the use of antidepressants had a significant impact on HRV. RSA was considerably decreased in patients who had started a TCA, serotonergic noradrenergic reuptake inhibitors (SNRIs), or SSRI relative to persistent antidepressant users. In contrast, when stopped an antidepressant, a significant increase was found in RSA. Such results are consistent with a recent large longitudinal study by O'Regan et al. [66], where reductions in HRV among the older adults with depression were closely relevant to the use of antidepressant medications such that SSRIs had less 
impact on HRV relative to other antidepressants such as TCAs or SNRIs, respectively. These inconsistent results on effect of antidepressant medication on HRV might have been driven by some methodological differences [50], thus well-defined and controlled studies are required for more clarification of the impact of depression and antidepressant medication on HRV.

\section{HRV in Schizophrenia}

Measurements of HRV have been widely used to assess altered cardiac autonomic regulation in patients with schizophrenia. Findings regarding HRV in patients with schizophrenia have not been consistent and depend on the severity of psychotic symptoms or medication use. The mechanisms by which vagal activity is restrained in schizophrenia are still unknown, but it has been speculated that disturbances in the cortico-subcortical circuits modulating the ANS may underlie the vagal dysfunction [67].

The majority of studies indicate that HRV in patients with schizophrenia is lower than that in healthy controls, which is indicative of autonomic dysfunction [61,67-69]. A recent meta-analysis showed that reduced HRV may provide an endophenotype for schizophrenia, and also implied that the endophenotype could play a vital role in both the prevention and treatment of schizophrenia [70]. Other studies have highlighted differences between LFand HF-HRV in schizophrenia. HF-HRV is significantly reduced in patients with schizophrenia when compared to healthy controls, while LF-HRV is not significantly different between patients with schizophrenia and healthy controls $[60,67,71]$. These results suggest that patients with schizophrenia have dysfunctions in the parasympathetic system and a relative preservation of sympathetic functioning when compared to healthy controls.

More interestingly, as in depression, the impact of the severity of psychotic symptoms on reduced HRV has been reported in patients with schizophrenia. The severity of psychotic symptoms, and especially cognitive/disorganization symptom dimensions, have been reported to have significant negative correlations with SDNN and RMSSD, suggesting that decreased parasympathetic function may be associated with the severity of these symptoms [67,72-74].

Concerns regarding potentially dangerous cardiac side effects of antipsychotic medications in schizophrenia have been raised. Several studies have reported that the use of atypical antipsychotics, particularly clozapine, is associated with reduced HRV [75-77]. However, one critical limitation of the above reports is that the studies on medication side effects did not include a medication-free group. Mujica-Parodi et al. [78] examined this issue to determine whether the cardiac effects of the medications are only the result of medication use or reflect an underlying vulnerability associated with schizophrenia (or psychosis) itself. These researchers compared medication-free patients with schizophrenia to medicated patients and healthy controls. They found reduced HRV in the medication-free patients when compared to healthy controls (the symptom severity between two groups was equivalent). This suggests that decreased vagal function exists independent of medication side effects, and is thus likely to be associated with the presence of schizophrenia or psychosis itself [79]. The results of the above study further indicate that reduced HRV in medicated patients (7 using clozapine and 3 using olanzapine) was significantly more severe than in patients in the medication-free group. This is consistent with a recent meta-analysis providing preliminary evidence for a particular negative effect of clozapine use in reducing HRV [80]. These findings imply that cardiac risk in schizophrenia may be exacerbated by mechanisms related to the use of psychotropics such as clozapine.

\section{HRV in PTSD}

Relatively few studies have examined HRV in patients with PTSD relative to those in patients with other kinds of psychiatric disorders. A series of studies conducted by Cohen et al. [81-84] showed that baseline autonomic hyperarousal was accompanied by reduced HF-HRV in patients with PTSD when compared to healthy controls. Elevated sympathetic tone and reduced parasympathetic tone were suggested as psychophysiological symptoms of PTSD. Like those on other psychiatric disorders, studies on HRV in PTSD have had inconsistent results. For example, several studies have reported reduced resting HRV in patients with PTSD when compared to healthy controls. [81,82,85-88] In contrast, other studies have reported no differences between patients with PTSD and healthy controls in HF-HRV $[89,90]$, while other studies have reported increased HF-HRV in men with PTSD when compared to men without PTSD [91]. 
The conflicting results might be due to relatively small sample sizes and differences in the use of medications, physical health, smoking, psychiatric comorbidities, and the use of different HRV measures. For example, PTSD is often associated with an increased risk of developing secondary comorbid disorders, such as depression [92]. Thus, factors concomitant with depression might influence the relationship between PTSD and HRV. In addition, smoking, alcohol overuse, and sleep disturbance have been reported to mediate the association between PTSD and HRV [93]. Chang et al. [94] tried to clarify the above issues by using large sample sizes (total of 256 subjects) and excluding subjects with psychiatric and physical comorbidities. In addition, they only used medication-free and non-smoker subjects. The frequency domain measures of HRV was obtained while lying supine for 5 minutes. The results of the above study, which had well-controlled subjects, revealed reduced HF-HRV in patients with PTSD when compared to both subjects with past trauma subjects and healthy controls. The association between the severity of symptoms and HRV was also observed in patients with PTSD. Patients with more severe PTSD symptoms tended to have lower HF-HRV than those with less severe PTSD symptoms [86,94].

Another issue related to HRV in patients with PTSD is whether different affective conditions influence the degree of HRV. When measuring HRV during baseline, traumatic, or neutral script-driven imagery, Sack et al. [95] found that individuals with PTSD had a significant decrease in HRV from baseline during the traumatic script, and that there was an association between low baseline HRV and sustained arousal in response to the traumatic cue. In contrast, when measuring HRV during the recounting of the traumatic event, Cohen et al. [82,84] found that patients with PTSD had reduced HRV throughout all stages of the trial, with no changes in HRV parameters between a resting period and the trauma reminder. Hauschildt et al. [86] have also reported that affective (including trauma-related) cues do not differentially influence HRV responses in subjects with PTSD when compared to healthy controls. These findings imply that emotional conditions may be not associated with changes in HRV (i.e., a rigid state HRV) in individuals with PTSD (but see meta-analyses by Buckley and Kaloupek [96], Pole [97]).

\section{HRV AND QEEG IN PSYCHIATRIC DISORDERS}

Analysis of the circadian variation of HRV has been considered as a way of examining abnormalities of autonomic activity [98]. For example, it was reported that patients with coronary artery disease lose primarily the circadian pattern because increases in HRV during the nighttime are blunted or absent [99]. These observations suggest that sleep may be the condition in which biomarkers such as HRV can best diagnose autonomic disturbances [100].

Twenty-four hour HRV typically shows an increase in the standard deviation of mean $\mathrm{R}-\mathrm{R}$ intervals during the night, indicating that overall vagal activity is dominant during sleep. It has been demonstrated that sleep is closely involved with rapid variations in the ANS [100-103]. HRV increases in the HF component and decreases in the LF during non-rapid eye movement (NREM) stages of sleep, and the opposite changes during REM sleep. The LF and LF/HF show a significant decrease as the sleep stage deepens. Considering these findings, it is suggested that the SNS is activated during REM sleep, and the PNS is activated during NREM sleep.

The type or stage of sleep is typically determined by EEG. Not only for the sake of sleep research, but also for noninvasively diagnosing mental illness, EEG has been considered a useful measurement [104-115]. The spectral analysis of EEG is used as a quantitative parameter of the depth of sleep [116]. Eye-closed resting-state qEEG reflects intrinsic brain activity [117-119]. In this section, we discuss the direct and indirect interplay between HRV components and EEG activity in patients with psychiatric disorders.

A sleep cohort study showed stronger time-dependent correlations between delta EEG and HF-HRV in individuals with sleep disturbance and insomnia when compared to healthy controls. Middle-aged women who are at increased risk for sleep disturbances and cardiometabolic disease displayed whole-night correlations among delta EEG power and HF-HRV, which were particularly strongly and positively correlated during NREM sleep [120].

Women with recurrent MDD have also been shown to have lower left frontal alpha activity, lower HF, and higher LF/HF ratio when compared to healthy controls. This reflects the presence of distinctive profiles of altered brain 
activity and decreased cardiovascular tone in individuals with depression [121]. The right hemisphere has been reported to modulate sympathetic tone [122], while the PNS is dominantly regulated by the left hemisphere [123]. Thus, the major pathophysiology in MDD is a neural circuit whereby both hemispheres counteract cardiac autonomic function, which may be disabled in MDD.

The relationship between HRV and EEG was investigated in a longitudinal study on whether frontal EEG activity during early childhood was associated with anxiety symptoms and emotion regulation during a stressful situation in middle childhood. Children who demonstrated left frontal EEG asymmetry in early childhood experienced less arousal (i.e., higher HRV) during situations that provoked anxiety. Conversely, children with right frontal EEG asymmetry in early childhood experienced greater arousal (i.e., lower HRV) during situations that provoked anxiety [124].

EEG and HRV have also been used as potential parameters in assessing whether biofeedback is effective for PTSD treatment. Veterans with PTSD have been reported to have higher peak alpha frequency $(8-12.99 \mathrm{~Hz})$ and lower peak frequencies of HF-HRV relative to healthy controls [125]. We also review other studies from our group showing a relationship between EEG and HRV. It has been reported that patients with PTSD have significantly lower HRV-LF and HF power when compared to healthy controls [81], as well as increased power in the theta and beta bands [126] and decreased power in the alpha band [127]. This connection between the heart and the brain is known to reflect the experience of emotions [128-130]. It was reported that traumatic experience may influence the heart-brain connection. Individuals with trauma history in childhood have increased beta frequency power in EEG in adulthood, as well as reduced HRV-LF power [131].

\section{COGNITIVE FUNCTIONING AND HRV}

HRV is known to be regulated by the PFC such that changes in PFC functioning is associated with changes in HRV measures [21]. Alteration of PFC activity has been demonstrated to modulate HRV using cognitive tasks based on prefrontal functioning [132]. In this section, we review the evidences that show the association between tasks known to predominantly engage regions of the PFC and HRV.

A dynamic interplay between the SNS and PNS is required for efficient functioning in complex situations. This interplay requires adequate PFC functioning, which is thought to be involved in the inhibition of SNS activation [30,133-136]. Decreased SNS and increased PNS activity are associated with high HRV (particularly HF-HRV) and high activity in the PFC [137]. A number of studies have provided neuroimaging evidence indicating that activity of the PFC is associated with HRV [137-141]. For example, Lane et al. [137] have showed that HF-HRV is positively associated with blood flow in the right superior PFC (Brodmann areas [BA] 8 and 9), left rostral ACC (BA 24 and 32), right dorsolateral PFC (DLPFC, BA 46), and right parietal cortex (BA 40). The DLPFC is well known to play a key role in working memory [142]. The right superior frontal cortex is known to be involved in executive control of attentional shifting [143], particularly in relation to working memory [144], as well as in monitoring the contextual significance of information retrieved from episodic memory [145]. In addition, ACC activity plays an important role in decision-making [146-148] and socially driven interactions $[147,149,150]$.

One common approach to study HRV and cognitive functioning has been to view HRV as a dependent variable [5]. Early studies have examined the relationship between HRV and attention in adults [151,152], older children [153], and even in newborn babies [154,155]. These studies have consistently demonstrated that HRV is significantly reduced during sustained attention. Recently, another approach to view HRV as an independent variable has become more prominent, leading to further studies on the predictive power of HRV on cognitive functioning. These studies have been mainly carried out by differentiating executive from nonexecutive functions.

While executive-function tasks require abilities localized in the PFC, nonexecutive-function tasks are based on processes driven automatically or reflexively by stimulation, as mentioned above [5]. Therefore, so the effects of $H R V$ on cognitive performance may differ depending on the types of processes required by the task. For example, Hansen et al. [156] have reported that subjects with high HRV perform better on executive tasks that require working memory and attention, although they do not differ when performing tasks based on simple reaction time when compared to subjects with low HRV. This is con- 
sistent with reports of correlations between higher PFC activity and better executive abilities [134,157].

The finding that a high level of HRV leads to outperformance in executive tasks reflects a better ability to adapt to environments in individuals with high HRV. Studies on the relationship between HRV and cognitive abilities have been conducted under stressful conditions or cognitive workload. During the threat of shock paradigm, where an individual anticipates an unpredictable and unpleasant electrical shock, subjects with high HRV had good stable performance on a working memory task (i.e., accuracy) regardless of the threat of shock. In contrast, subjects with low HRV had improved reaction times during the threat of shock [158]. The consistent performance on cognitive tasks in the high-HRV group might be explained by high vagal tone, which is associated with the ability to maintain self-regulation and enhance behavioral flexibility and adaptability in a threatening environment. In contrast, it seems that the low-HRV group was more vulnerable to environmental conditions such as stress [5].

It has been reported that individuals with low HRV are more susceptible to cognitive workload $[156,159]$. When saliva cortical levels were measured during cognitive tests, cortisol levels in the low-HRV group were significantly higher than in the high-HRV group, although there was no difference between the two HRV groups during morning, baseline, and evening recordings [160]. This finding implies that HRV is associated with susceptibility to cognitive stress, and that it plays a critical role in cognitive stress, as well as in cognitive performance.

However, the association between HRV and executive functions is not always found. For example, Britton et al. [161] reported that low HRV in middle-aged population is not associated with aspects of poor cognitive function (see also Jennings et al. [162] in 2015). Duschek et al. [163] (2009) also presented the results that rather reduced HRV is associated with better cognitive performance. In addition, there were cases that such association between HRV and cognitive performance disappears after demographic factors such as age, sex, education, and body mass index are adjusted [164,165].

If so, another important question is whether it would be possible to manipulate HRV to enhance cognitive functioning. Several studies on HRV indicate that pharmacological interventions [166,167] and behaviorally based programs $[168,169]$ can alter HRV. For example, Luque-
Casado et al. [169] (2013) examined the impact of fitness level on cognitive performance and HRV. When compared to a low-fitness group, individuals in a high-fitness group had better performance in a sustained attention task, as well as greater vagal control of HRV parameters both at rest and during performance of the cognitive task. This was presumably a result of aerobic training. In addition, individuals in the low-fitness group displayed a gradual decrement in HRV as a function of the time spent on the task, indicating that the high-fitness group was more resistant to the time spent on the task. These findings suggest that fitness level may be a key factor regulating cardiac autonomic control (i.e., leading to higher HRV) and cognitive performance.

Hansen et al. [170] have also compared the effects of training and detraining on cognitive functioning. After a training program was provided, half of the subjects quit the program (i.e., detraining group), while the other half continued (i.e., training group). The detraining group exhibited lower HF-HRV when compared to the training group. In addition, the detraining group had faster reaction times to nonexecutive tasks, while the training group had faster reaction times and higher accuracy in executive-function tasks. Taken together, these results suggest that engaging in exercise may be a critical factors leading to improvements in executive functioning.

\section{CONCLUSIONS}

In this review, we aimed to examine the effects of psychiatric disorders on HRV. We were interested in HRV abnormalities in patients with MDD, schizophrenia, and PTSD when compared to healthy controls, the meanings of abnormalities in HRV, and the associations between HRV and EEG, as well as those between HRV and cognitive functioning. We review evidence that HRV is not only a risk marker for CVD, but that also decreases in HRV have close associations with depression, schizophrenia, and PTSD.

Cross-disorder findings from patients with MDD, schizophrenia, and PTSD support a key role for HRV in mental and physical well-being. Research on depression indicates that MDD is associated with CVD mortality, such that reduced HRV is a feature of both CVD and MDD. Reduced HRV in patients with MDD reflects an impairment of autonomic nervous function. More importantly, it 
has been consistently reported that the severity of depression is associated with the degree of HRV abnormality. Patients with more severe depression are likely to have lower HRV than those with less severe depression. Such an association was also apparent in patients with schizophrenia and in those with PTSD.

The degree of HRV in patients with schizophrenia differed depending on the ANS considered. HF-HRV was significantly reduced in patients with schizophrenia when compared to healthy controls, while LF-HRV was not significantly reduced in patients with schizophrenia. This implies that schizophrenia is associated with dysfunction in parasympathetic functioning and a relative preservation of sympathetic functioning. Patients with PTSD have reduced HF-HRV due to high levels of anxiety and emotion dysregulation. The defeat of parasympathetic tone may lead to hyperarousal symptoms, which are mediated by anxiety level and greater alpha band activation in the right hemisphere.

We also present evidence in support of the notion that $\mathrm{HRV}$ is associated with individual differences in cognitive performance, and particularly executive function. First, we reviewed the neural basis for such an association, which suggests that prefrontal neural function is related to HRV. We then provided a review of studies that examining the functional relationship between HRV and executive function. We found evidence for an association between higher levels of resting HRV during diverse cognitive tasks. This indicates that higher HRV is associated with superior performance on tasks that test executive functions, while the degree of HRV was not associated with performance on nonexecutive function tasks.

Given the importance of these findings for understanding the ANS in psychiatric disorders, further research is required to assess the implications of reduced HRV. The evidence reviewed here suggests that chronic reductions in HRV are closely linked to impairments in a system that increases the risks of CVD, mortality, and mental illness. We suggest that interventions leading to increased HRV should be considered in healthy controls with cardiovascular risk, as well as in patients with psychiatric illness. In addition, considerable further work is required to assess medication effects, as the degree of HRV depends on the type of medication used in schizophrenia. In conclusion, HRV provides a tool to easily assess and measure mental illness and future health.

\section{Acknowledgments}

This work was supported by a grant from the Korea Science and Engineering Foundation (KOSEF), funded by the Korean government (NRF-2018R1A2A2A05018505), and by the 2018 creative research program of Inje University.

\section{- Conflicts of Interest}

No potential conflict of interest relevant to this article was reported.

\section{- Author Contributions}

Conceptualization: Wookyoung Jung, Seung-Hwan Lee. Data acquisition: Wookyoung Jung, Kuk-In Jang. Formal analysis: Wookyoung Jung, Kuk-In Jang. Funding: Seung-Hwan Lee. Supervision: Seung-Hwan Lee. Writing-original draft: Wookyoung Jung, Kuk-In Jang. Writing-review \& editing: Wookyoung Jung, Seung-Hwan Lee.

\section{ORCID}

Wookyoung Jung https://orcid.org/0000-0001-6208-6848

Kuk-In Jang https://orcid.org/0000-0002-7405-3899

Seung-Hwan Lee https://orcid.org/0000-0003-0305-3709

\section{REFERENCES}

1. Berntson GG, Bigger JT Jr, Eckberg DL, Grossman P, Kaufmann PG, Malik M, et al. Heart rate variability: origins, methods, and interpretive caveats. Psychophysiology 1997; 34:623-648.

2. McCorry LK. Physiology of the autonomic nervous system. Am J Pharm Educ 2007;71:78.

3. McCraty R, Shaffer F. Heart rate variability: new perspectives on physiological mechanisms, assessment of self-regulatory capacity, and health risk. Glob Adv Health Med 2015:4:4661.

4. Singer DH, Martin GJ, Magid N, Weiss JS, Schaad JW, Kehoe $\mathrm{R}$, et al. Low heart rate variability and sudden cardiac death. J Electrocardiol 1988;21 Suppl:S46-S55.

5. Thayer JF, Hansen AL, Saus-Rose E, Johnsen BH. Heart rate variability, prefrontal neural function, and cognitive performance: the neurovisceral integration perspective on self-regulation, adaptation, and health. Ann Behav Med 2009;37:141-153.

6. Sztajzel J. Heart rate variability: a noninvasive electrocardiographic method to measure the autonomic nervous system. Swiss Med Wkly 2004;134:514-522.

7. Niskanen JP, Tarvainen MP, Ranta-Aho PO, Karjalainen PA. 
Software for advanced HRV analysis. Comput Methods Programs Biomed 2004; 76:73-81.

8. Malliani A, Lombardi F, Pagani M. Power spectrum analysis of heart rate variability: a tool to explore neural regulatory mechanisms. Br Heart J 1994; 71:1-2.

9. Eckberg DL. Sympathovagal balance: a critical appraisal. Circulation 1997; 96:3224-3232.

10. Kuusela T. Methodological aspects of heart rate variability analysis. In: Kamath MV, Watanabe M, Upton A, eds. Heart rate variability (HRV) signal analysis: clinical applications. Boca Raton:CRC Press;2013. p. 10-42.

11. Beckers F, Ramaekers D, Aubert AE. Approximate entropy of heart rate variability: validation of methods and application in heart failure. Cardiovasc Eng 2001;1:177-182.

12. Malliani A, Pagani M, Lombardi F, Cerutti S. Cardiovascular neural regulation explored in the frequency domain. Circulation 1991;84:482-492.

13. Pagani M, Lombardi F, Guzzetti S, Rimoldi O, Furlan R, Pizzinelli $\mathrm{P}$, et al. Power spectral analysis of heart rate and arterial pressure variabilities as a marker of sympatho-vagal interaction in man and conscious dog. Circ Res 1986;59:178193.

14. Reyes del Paso GA, Langewitz W, Mulder LJ, van Roon A, Duschek S. The utility of low frequency heart rate variability as an index of sympathetic cardiac tone: a review with emphasis on a reanalysis of previous studies. Psychophysiology 2013;50:477-487.

15. Houle MS, Billman GE. Low-frequency component of the heart rate variability spectrum: a poor marker of sympathetic activity. Am J Physiol 1999;276:H215-H223.

16. Levy MN. Autonomic interactions in cardiac control. Ann N Y Acad Sci 1990;601:209-221.

17. Malik M, Bigger JT, Camm J, Kleiger RE, Malliani A, Moss AJ, et al. Heart rate variability. Standards of measurement, physiological interpretation, and clinical use. Task Force of the European Society of Cardiology and the North American Society of Pacing and Electrophysiology. Eur Heart J 1996; 17:354-381.

18. Nolan J, Batin PD, Andrews R, Lindsay SJ, Brooksby P, Mullen $\mathrm{M}$, et al. Prospective study of heart rate variability and mortality in chronic heart failure: results of the United Kingdom heart failure evaluation and assessment of risk trial (UK-heart). Circulation 1998;98:1510-1516.

19. de Bruyne MC, Kors JA, Hoes AW, Klootwijk P, Dekker JM, Hofman A, et al. Both decreased and increased heart rate variability on the standard 10-second electrocardiogram predict cardiac mortality in the elderly: the Rotterdam Study. Am J Epidemiol 1999;150:1282-1288.

20. Dekker JM, Schouten EG, Klootwijk P, Pool J, Swenne CA, Kromhout D. Heart rate variability from short electrocardiographic recordings predicts mortality from all causes in middle-aged and elderly men. The Zutphen Study. Am J Epidemiol 1997;145:899-908.
21. Thayer JF, Sternberg E. Beyond heart rate variability: vagal regulation of allostatic systems. Ann N Y Acad Sci 2006; 1088:361-372.

22. Thayer JF, Lane RD. The role of vagal function in the risk for cardiovascular disease and mortality. Biol Psychol 2007; 74: 224-242.

23. La Rovere MT, Pinna GD, Maestri R, Mortara A, Capomolla $\mathrm{S}$, Febo $\mathrm{O}$, et al. Short-term heart rate variability strongly predicts sudden cardiac death in chronic heart failure patients. Circulation 2003;107:565-570.

24. Hillebrand S, Gast KB, de Mutsert R, Swenne CA, Jukema JW, Middeldorp S, et al. Heart rate variability and first cardiovascular event in populations without known cardiovascular disease: meta-analysis and dose-response metaregression. Europace 2013;15:742-749.

25. Barch D. 7. The neural mechanisms of cognitive control in psychosis. Schizophr Bull 2017;43(Supp/ 1):S9.

26. Zalesky A, Fornito A, Seal ML, Cocchi L, Westin CF, Bullmore ET, et al. Disrupted axonal fiber connectivity in schizophrenia. Biol Psychiatry 2011;69:80-89.

27. Do J, Woo J. From gut to brain: alteration in inflammation markers in the brain of dextran sodium sulfate-induced colitis model mice. Clin Psychopharmacol Neurosci 2018; 16:422-433.

28. Dumont M, Jurysta F, Lanquart JP, Noseda A, van de Borne $\mathrm{P}$, Linkowski P. Scale-free dynamics of the synchronization between sleep EEG power bands and the high frequency component of heart rate variability in normal men and patients with sleep apnea-hypopnea syndrome. Clin Neurophysiol 2007;118:2752-2764.

29. da Silva VP, Ramalho Oliveira BR, Tavares Mello RG, Moraes $\mathrm{H}$, Deslandes AC, Laks J. Heart rate variability indexes in dementia: a systematic review with a quantitative analysis. Curr Alzheimer Res 2018;15:80-88.

30. Thayer JF, Lane RD. Claude Bernard and the heart-brain connection: further elaboration of a model of neurovisceral integration. Neurosci Biobehav Rev 2009;33:81-88.

31. Shaffer F, McCraty R, Zerr CL. A healthy heart is not a metronome: an integrative review of the heart's anatomy and heart rate variability. Front Psychol 2014;5:1040.

32. Nikolin S, Boonstra TW, Loo CK, Martin D. Combined effect of prefrontal transcranial direct current stimulation and a working memory task on heart rate variability. PLoS One 2017;12:e0181833.

33. Mashin VA, Mashina MN. Analysis of the heart rate variability in negative functional states in the course of psychological relaxation sessions. Hum Physiol 2000;26:420.

34. Appelhans BM, Luecken LJ. Heart rate variability and pain: associations of two interrelated homeostatic processes. Biol Psychol 2008;77:174-182.

35. Appelhans BM, Luecken LJ. Heart rate variability as an index of regulated emotional responding. Rev Gen Psychol 2006; 10:229-240. 
36. Frazier TW, Strauss ME, Steinhauer SR. Respiratory sinus arrhythmia as an index of emotional response in young adults. Psychophysiology 2004;41:75-83.

37. Urakawa K, Yokoyama K. Music can enhance exerciseinduced sympathetic dominancy assessed by heart rate variability. Tohoku J Exp Med 2005;206:213-218.

38. Chambers AS, Allen JJ. Vagal tone as an indicator of treatment response in major depression. Psychophysiology 2002; 39:861-864.

39. Riganello F, Dolce G, Garbarino S, Sannita W. Heart rate variability and the two-way interaction between CNS and the central autonomic network. Exp Clin Cardiol 2014;20: 5584-5595.

40. Carney RM, Rich MW, Tevelde A, Saini J, Clark K, Jaffe AS. Major depressive disorder in coronary artery disease. Am J Cardiol 1987;60:1273-1275.

41. Gonzalez MB, Snyderman TB, Colket JT, Arias RM, Jiang JW, $\mathrm{O}^{\prime}$ Connor CM, et al. Depression in patients with coronary artery disease. Depression 1996;4:57-62.

42. Pratt LA, Ford DE, Crum RM, Armenian HK, Gallo JJ, Eaton WW. Depression, psychotropic medication, and risk of myocardial infarction. Prospective data from the Baltimore ECA follow-up. Circulation 1996;94:3123-3129.

43. Anda R, Williamson D, Jones D, Macera C, Eaker E, Glassman A, et al. Depressed affect, hopelessness, and the risk of ischemic heart disease in a cohort of U.S. adults. Epidemiology 1993;4:285-294.

44. Barefoot JC, Helms MJ, Mark DB, Blumenthal JA, Califf RM, Haney TL, et al. Depression and long-term mortality risk in patients with coronary artery disease. Am J Cardiol 1996; 78 : 613-617.

45. Penninx BW, Beekman AT, Honig A, Deeg DJ, Schoevers RA, van Eijk JT, et al. Depression and cardiac mortality: results from a community-based longitudinal study. Arch Gen Psychiatry 2001;58:221-227.

46. Agelink MW, Boz C, Ullrich H, Andrich J. Relationship between major depression and heart rate variability. Clinical consequences and implications for antidepressive treatment. Psychiatry Res 2002;113:139-149.

47. Hon EH, Lee ST. Electronic evaluation of the fetal heart rate. Viii. Patterns preceding fetal death, further observations. Am J Obstet Gynecol 1963;87:814-826.

48. Reynard A, Gevirtz R, Berlow R, Brown M, Boutelle K. Heart rate variability as a marker of self-regulation. Appl Psychophysiol Biofeedback 2011;36:209-215.

49. Segerstrom SC, Nes LS. Heart rate variability reflects self-regulatory strength, effort, and fatigue. Psychol Sci 2007;18: 275-281.

50. Kemp AH, Quintana DS, Gray MA, Felmingham KL, Brown K, Gatt JM. Impact of depression and antidepressant treatment on heart rate variability: a review and meta-analysis. Biol Psychiatry 2010;67:1067-1074.

51. Rottenberg J. Cardiac vagal control in depression: a critical analysis. Biol Psychol 2007;74:200-211.

52. Koenig J, Kemp AH, Beauchaine TP, Thayer JF, Kaess M. Depression and resting state heart rate variability in children and adolescents - a systematic review and meta-analysis. Clin Psychol Rev 2016;46:136-150.

53. Dalack GW, Roose SP. Perspectives on the relationship between cardiovascular disease and affective disorder. J Clin Psychiatry 1990;51 Suppl:4-9; discussion 10-11.

54. Rechlin T, Weis M, Claus D. Heart rate variability in depressed patients and differential effects of paroxetine and amitriptyline on cardiovascular autonomic functions. Pharmacopsychiatry 1994;27:124-128.

55. Guinjoan SM, Bernabó JL, Cardinali DP. Cardiovascular tests of autonomic function and sympathetic skin responses in patients with major depression. I Neurol Neurosurg Psychiatry 1995;59:299-302.

56. Tulen JH, Bruijn JA, de Man KJ, van der Velden E, Pepplinkhuizen L, Man in 't Veld AJ. Anxiety and autonomic regulation in major depressive disorder: an exploratory study. J Affect Disord 1996:40:61-71.

57. Stein PK, Carney RM, Freedland KE, Skala JA, Jaffe AS, Kleiger RE, et al. Severe depression is associated with markedly reduced heart rate variability in patients with stable coronary heart disease. J Psychosom Res 2000;48:493-500.

58. Yeragani VK, Pohl R, Balon R, Ramesh C, Glitz D, Jung I, et al. Heart rate variability in patients with major depression. Psychiatry Res 1991;37:35-46.

59. Moser $M$, Lehofer $M$, Hoehn-Saric R, McLeod DR, Hildebrandt G, Steinbrenner B, et al. Increased heart rate in depressed subjects in spite of unchanged autonomic balance? J Affect Disord 1998:48:115-124.

60. Moon E, Lee SH, Kim DH, Hwang B. Comparative study of heart rate variability in patients with schizophrenia, bipolar disorder, post-traumatic stress disorder, or major depressive disorder. Clin Psychopharmacol Neurosci 2013;11:137-143.

61. van ZyI LT, Hasegawa T, Nagata K. Effects of antidepressant treatment on heart rate variability in major depression: a quantitative review. Biopsychosoc Med 2008;2:12.

62. Lederbogen F, Gernoth C, Weber B, Colla M, Kniest A, Heuser I, et al. Antidepressive treatment with amitriptyline and paroxetine: comparable effects on heart rate variability. J Clin Psychopharmacol 2001;21:238-239.

63. Khaykin Y, Dorian P, Baker B, Shapiro C, Sandor P, Mironov $\mathrm{D}$, et al. Autonomie correlates of antidepressant treatment using heart-rate variability analysis. Can J Psychiatry 1998; 43:183-186.

64. Licht CM, de Geus EJ, Zitman FG, Hoogendijk WJ, van Dyck R, Penninx BW. Association between major depressive disorder and heart rate variability in the Netherlands Study of Depression and Anxiety (NESDA). Arch Gen Psychiatry 2008; 65:1358-1367.

65. Licht CM, de Geus EJ, van Dyck R, Penninx BW. Longitudinal evidence for unfavorable effects of antidepres- 
sants on heart rate variability. Biol Psychiatry 2010;68:861868.

66. O'Regan C, Kenny RA, Cronin H, Finucane C, Kearney PM. Antidepressants strongly influence the relationship between depression and heart rate variability: findings from the Irish Longitudinal Study on Ageing (TILDA). Psychol Med 2015; 45:623-636.

67. Bär KJ, Letzsch A, Jochum T, Wagner G, Greiner W, Sauer H. Loss of efferent vagal activity in acute schizophrenia. J Psychiatr Res 2005;39:519-527.

68. Chang JS, Yoo CS, Yi SH, Hong KH, Oh HS, Hwang JY, et al. Differential pattern of heart rate variability in patients with schizophrenia. Prog Neuropsychopharmacol Biol Psychiatry 2009;33:991-995.

69. Jindal R, MacKenzie EM, Baker GB, Yeragani VK. Cardiac risk and schizophrenia. J Psychiatry Neurosci 2005;30:393395.

70. Clamor A, Lincoln TM, Thayer JF, Koenig J. Resting vagal activity in schizophrenia: meta-analysis of heart rate variability as a potential endophenotype. Br I Psychiatry 2016;208: 9-16.

71. Valkonen-Korhonen $\mathrm{M}$, Tarvainen MP, Ranta-Aho $\mathrm{P}$, Karjalainen PA, Partanen J, Karhu J, et al. Heart rate variability in acute psychosis. Psychophysiology 2003;40:716726.

72. Hempel RJ, Tulen JH, van Beveren NJ, Röder CH, Hengeveld MW. Cardiovascular variability during treatment with haloperidol, olanzapine or risperidone in recent-onset schizophrenia. J Psychopharmacol 2009;23:697-707.

73. $\mathrm{Kim} \mathrm{JH}, \mathrm{Ann} \mathrm{JH}$, Lee J. Relationship between heart rate variability and the severity of psychotic symptoms in schizophrenia. Acta Neuropsychiatr 2011;23:161-166.

74. Chung MS, Yang AC, Lin YC, Lin CN, Chang FR, Shen SH, et al. Association of altered cardiac autonomic function with psychopathology and metabolic profiles in schizophrenia. Psychiatry Res 2013;210:710-715.

75. Cohen H, Loewenthal U, Matar M, Kotler M. Association of autonomic dysfunction and clozapine. Heart rate variability and risk for sudden death in patients with schizophrenia on long-term psychotropic medication. Br J Psychiatry 2001; 179:167-171.

76. Mueck-Weymann M, Rechlin T, Ehrengut F, Rauh R, Acker J, Dittmann RW, et al. Effects of olanzapine and clozapine upon pulse rate variability. Depress Anxiety 2002;16:93-99.

77. Rechlin T, Beck G, Weis M, Kaschka WP. Correlation between plasma clozapine concentration and heart rate variability in schizophrenic patients. Psychopharmacology (Berl) 1998; 135:338-341.

78. Mujica-Parodi LR, Yeragani V, Malaspina D. Nonlinear complexity and spectral analyses of heart rate variability in medicated and unmedicated patients with schizophrenia. Neuropsychobiology 2005;51:10-15.

79. Malaspina D, Dalack G, Leitman D, Corcoran C, Amador
$\mathrm{XF}$, Yale S, et al. Low heart rate variability is not caused by typical neuroleptics in schizophrenia patients. CNS Spectr 2002; 7:53-57.

80. Alvares GA, Quintana DS, Hickie IB, Guastella AJ. Autonomic nervous system dysfunction in psychiatric disorders and the impact of psychotropic medications: a systematic review and meta-analysis. J Psychiatry Neurosci 2016;41:89104.

81. Cohen H, Kotler M, Matar MA, Kaplan Z, Miodownik H, Cassuto Y. Power spectral analysis of heart rate variability in posttraumatic stress disorder patients. Biol Psychiatry 1997; 41:627-629.

82. Cohen H, Kotler M, Matar MA, Kaplan Z, Loewenthal U, Miodownik $\mathrm{H}$, et al. Analysis of heart rate variability in posttraumatic stress disorder patients in response to a trauma-related reminder. Biol Psychiatry 1998;44:1054-1059.

83. Cohen $\mathrm{H}$, Kotler M, Matar M, Kaplan Z. Normalization of heart rate variability in post-traumatic stress disorder patients following fluoxetine treatment: preliminary results. Isr Med Assoc J 2000;2:296-301.

84. Cohen H, Benjamin J, Geva AB, Matar MA, Kaplan Z, Kotler M. Autonomic dysregulation in panic disorder and in posttraumatic stress disorder: application of power spectrum analysis of heart rate variability at rest and in response to recollection of trauma or panic attacks. Psychiatry Res 2000;96: 1-13.

85. Blechert J, Michael T, Grossman P, Lajtman M, Wilhelm FH. Autonomic and respiratory characteristics of posttraumatic stress disorder and panic disorder. Psychosom Med 2007; 69:935-943.

86. Hauschildt M, Peters MJ, Moritz S, Jelinek L. Heart rate variability in response to affective scenes in posttraumatic stress disorder. Biol Psychol 2011;88:215-222.

87. Hopper JW, Spinazzola J, Simpson WB, van der Kolk BA. Preliminary evidence of parasympathetic influence on basal heart rate in posttraumatic stress disorder. I Psychosom Res 2006;60:83-90.

88. Tan G, Fink B, Dao TK, Hebert R, Farmer LS, Sanders A, et al. Associations among pain, PTSD, $m$ TBI, and heart rate variability in veterans of Operation Enduring and Iraqi Freedom: a pilot study. Pain Med 2009;10:1237-1245.

89. Keary TA, Hughes JW, Palmieri PA. Women with posttraumatic stress disorder have larger decreases in heart rate variability during stress tasks. Int I Psychophysiol 2009;73: 257-264.

90. Sahar T, Shalev AY, Porges SW. Vagal modulation of responses to mental challenge in posttraumatic stress disorder. Biol Psychiatry 2001;49:637-643.

91. Kamkwalala A, Norrholm SD, Poole JM, Brown A, Donley S, Duncan E, et al. Dark-enhanced startle responses and heart rate variability in a traumatized civilian sample: putative sex-specific correlates of posttraumatic stress disorder. Psychosom Med 2012;74:153-159. 
92. Ballenger JC, Davidson JR, Lecrubier Y, Nutt DJ, Foa EB, Kessler RC, et al. Consensus statement on posttraumatic stress disorder from the International Consensus Group on Depression and Anxiety. I Clin Psychiatry 2000;61 Suppl 5:60-66.

93. Dennis PA, Watkins LL, Calhoun PS, Oddone A, Sherwood A, Dennis MF, et al. Posttraumatic stress, heart rate variability, and the mediating role of behavioral health risks. Psychosom Med 2014;76:629-637.

94. Chang HA, Chang CC, Tzeng NS, Kuo TB, Lu RB, Huang SY. Decreased cardiac vagal control in drug-naïve patients with posttraumatic stress disorder. Psychiatry Investig 2013;10: 121-130.

95. Sack M, Hopper JW, Lamprecht F. Low respiratory sinus arrhythmia and prolonged psychophysiological arousal in posttraumatic stress disorder: heart rate dynamics and individual differences in arousal regulation. Biol Psychiatry 2004;55:284-290.

96. Buckley TC, Kaloupek DG. A meta-analytic examination of basal cardiovascular activity in posttraumatic stress disorder. Psychosom Med 2001;63:585-594.

97. Pole N. The psychophysiology of posttraumatic stress disorder: a meta-analysis. Psychol Bull 2007;133:725-746.

98. Malik M, Farrell T, Camm AJ. Circadian rhythm of heart rate variability after acute myocardial infarction and its influence on the prognostic value of heart rate variability. Am J Cardiol 1990;66:1049-1054.

99. Huikuri HV, Niemelä MJ, Ojala S, Rantala A, Ikäheimo MJ, Airaksinen KE. Circadian rhythms of frequency domain measures of heart rate variability in healthy subjects and patients with coronary artery disease. Effects of arousal and upright posture. Circulation 1994;90:121-126.

100. Vanoli E, Adamson PB, Ba-Lin, Pinna GD, Lazzara R, Orr WC. Heart rate variability during specific sleep stages. A comparison of healthy subjects with patients after myocardial infarction. Circulation 1995;91:1918-1922.

101. Tsunoda M, Endo T, Hashimoto S, Honma S, Honma KI. Effects of light and sleep stages on heart rate variability in humans. Psychiatry Clin Neurosci 2001;55:285-286.

102. Bonnet MH, Arand DL. Heart rate variability: sleep stage, time of night, and arousal influences. Electroencephalogr Clin Neurophysiol 1997;102:390-396.

103. Scholz UJ, Bianchi AM, Cerutti S, Kubicki S. Vegetative background of sleep: spectral analysis of the heart rate variability. Physiol Behav 1997;62:1037-1043.

104. Kupfer DJ, Foster FG, Coble P, McPartland RJ, Ulrich RF. The application of EEG sleep for the differential diagnosis of affective disorders. Am J Psychiatry 1978;135:69-74.

105. Feinberg M, Gillin JC, Carroll BJ, Greden JF, Zis AP. EEG studies of sleep in the diagnosis of depression. Biol Psychiatry 1982;17:305-316.

106. Shagass C, Roemer RA, Straumanis JJ. Relationships between psychiatric diagnosis and some quantitative EEG variables.
Arch Gen Psychiatry 1982;39:1423-1435.

107. Boutros NN, Arfken C, Galderisi S, Warrick J, Pratt G, lacono W. The status of spectral EEG abnormality as a diagnostic test for schizophrenia. Schizophr Res 2008;99:225-237.

108. Ford MR, Goethe JW, Dekker DK. EEG coherence and power in the discrimination of psychiatric disorders and medication effects. Biol Psychiatry 1986;21:1175-1188.

109. Shagass C, Roemer RA, Straumanis JJ, Josiassen RC. Psychiatric diagnostic discriminations with combinations of quantitative EEG variables. Br J Psychiatry 1984;144:581592.

110. Pollock VE, Schneider LS. Quantitative, waking EEG research on depression. Biol Psychiatry 1990;27:757-780.

111. Nusslock R, Shackman AJ, McMenamin BW, Greischar LL, Davidson RJ, Kovacs M. Comorbid anxiety moderates the relationship between depression history and prefrontal EEG asymmetry. Psychophysiology 2018;55:e12953.

112. Loo SK, McGough JJ, McCracken JT, Smalley SL. Parsing heterogeneity in attention-deficit hyperactivity disorder using EEG-based subgroups. J Child Psychol Psychiatry 2018;59: 223-231.

113. Shim M, Im CH, Kim YW, Lee SH. Altered cortical functional network in major depressive disorder: a resting-state electroencephalogram study. Neuroimage Clin 2018;19:1000-1007.

114. Swatzyna RJ, Tarnow JD, Turner RP, Roark AJ, Maclnerney $\mathrm{EK}$, Kozlowski GP. Integration of EEG into psychiatric practice: a step toward precision medicine for autism spectrum disorder. J Clin Neurophysiol 2017;34:230-235.

115. Kim JW, Kim SY, Choi JW, Kim KM, Nam SH, Min KJ, et al. Differences in resting-state quantitative electroencephalography patterns in attention deficit/hyperactivity disorder with or without comorbid symptoms. Clin Psychopharmacol Neurosci 2017;15:138-145.

116. Miyashita $T$, Ogawa $K$, Itoh $H$, Arai $\mathrm{Y}$, Ashidagawa $M$, Uchiyama $M$, et al. Spectral analyses of electroencephalography and heart rate variability during sleep in normal subjects. Auton Neurosci 2003;103:114-120.

117. Barlow JS. Rhythmic activity induced by photic stimulation in relation to intrinsic alpha activity of the brain in man. Electroencephalogr Clin Neurophysiol 1960;12:317-326.

118. Laufs H, Kleinschmidt A, Beyerle A, Eger E, Salek-Haddadi A, Preibisch C, et al. EEG-correlated $\mathrm{FMRI}$ of human alpha activity. Neuroimage 2003;19:1463-1476.

119. Boly M, Phillips C, Tshibanda L, Vanhaudenhuyse A, Schabus M, Dang-Vu TT, et al. Intrinsic brain activity in altered states of consciousness: how conscious is the default mode of brain function? Ann N Y Acad Sci 2008;1129:119129.

120. Rothenberger SD, Krafty RT, Taylor BJ, Cribbet MR, Thayer $\mathrm{JF}$, Buysse DJ, et al. Time-varying correlations between delta EEG power and heart rate variability in midlife women: the SWAN Sleep Study. Psychophysiology 2015;52:572-584.

121. Chang JS, Yoo CS, Yi SH, Her JY, Choi HM, Ha TH, et al. An 
integrative assessment of the psychophysiologic alterations in young women with recurrent major depressive disorder. Psychosom Med 2012; 74:495-500.

122. Yoon BW, Morillo CA, Cechetto DF, Hachinski V. Cerebral hemispheric lateralization in cardiac autonomic control. Arch Neurol 1997; 54:741-744.

123. Hilz MJ, Dütsch M, Perrine K, Nelson PK, Rauhut U, Devinsky O. Hemispheric influence on autonomic modulation and baroreflex sensitivity. Ann Neurol 2001;49:575584.

124. Hannesdóttir DK, Doxie J, Bell MA, Ollendick TH, Wolfe CD. A longitudinal study of emotion regulation and anxiety in middle childhood: associations with frontal EEG asymmetry in early childhood. Dev Psychobiol 2010;52:197-204.

125. Wahbeh H, Oken BS. Peak high-frequency HRV and peak alpha frequency higher in PTSD. Appl Psychophysiol Biofeedback 2013;38:57-69.

126. Begić D, Hotujac L, Jokić-Begić N. Electroencephalographic comparison of veterans with combat-related post-traumatic stress disorder and healthy subjects. Int I Psychophysiol 2001;40:167-172.

127. Jokić-Begić N, Begić D. Quantitative electroencephalogram (qEEG) in combat veterans with post-traumatic stress disorder (PTSD). Nord I Psychiatry 2003;57:351-355.

128. Bechara A, Naqvi N. Listening to your heart: interoceptive awareness as a gateway to feeling. Nat Neurosci 2004;7: 102-103.

129. Critchley HD, Wiens S, Rotshtein P, Ohman A, Dolan RJ. Neural systems supporting interoceptive awareness. Nat Neurosci 2004;7:189-195.

130. McCraty R. Heart-brain neurodynamics: the making of emotions. Boulder Creek, CA:Institute of Heart Math Publication;2003. p.3-15.

131. Jin MJ, Kim JS, Kim S, Hyun MH, Lee SH. An integrated model of emotional problems, beta power of electroencephalography, and low frequency of heart rate variability after childhood trauma in a non-clinical sample: a path analysis study. Front Psychiatry 2018;8:314.

132. Laborde S, Furley $P$, Schempp C. The relationship between working memory, reinvestment, and heart rate variability. Physiol Behav 2015;139:430-436.

133. Friedman BH. An autonomic flexibility-neurovisceral integration model of anxiety and cardiac vagal tone. Biol Psychol 2007;74:185-199.

134. Thayer JF, Brosschot JF. Psychosomatics and psychopatho/ogy: looking up and down from the brain. Psychoneuroendocrinology 2005;30:1050-1058.

135. Thayer JF, Friedman BH. Stop that! Inhibition, sensitization, and their neurovisceral concomitants. Scand J Psychol 2002; 43:123-130.

136. Jeon H, Lee $\mathrm{SH}$. From neurons to social beings: short review of the mirror neuron system research and its socio-psychological and psychiatric implications. Clin Psychopharmacol
Neurosci 2018;16:18-31.

137. Lane RD, McRae K, Reiman EM, Chen K, Ahern GL, Thayer JF. Neural correlates of heart rate variability during emotion. Neuroimage 2009;44:213-222.

138. Gianaros PJ, Van Der Veen FM, Jennings JR. Regional cerebral blood flow correlates with heart period and high-frequency heart period variability during working-memory tasks: implications for the cortical and subcortical regulation of cardiac autonomic activity. Psychophysiology 2004;41: 521-530.

139. Lane RD, Weidenbacher $\mathrm{H}$, Fort $\mathrm{CL}$, Thayer JF, Allen JJB. Subgenual anterior cingulate (BA25) activity covaries with changes in cardiac vagal tone during affective set shifting in healthy adults. Psychosom Med 2008;70:A-42.

140. Nugent AC, Bain EE, Thayer JF, Drevets WC. Anatomical correlates of autonomic control during a motor task. Psychosom Med 2007; 69:A-74.

141. Nugent AC, Bain EE, Sollers JJ, Thaye rJF, Drevets WC. Alterations in neural correlates of autonomic control in females with major depressive disorder. Psychosom Med 2008;70:A-99.

142. Goldman-Rakic PS. Regional and cellular fractionation of working memory. Proc Natl Acad Sci U S A 1996;93:1347313480.

143. Nagahama $Y$, Okada T, Katsumi $Y$, Hayashi T, Yamauchi $\mathrm{H}$, Sawamoto N, et al. Transient neural activity in the medial superior frontal gyrus and precuneus time locked with attention shift between object features. Neuroimage 1999;10: 193-199.

144. Milham MP, Banich MT, Webb A, Barad V, Cohen NJ, Wszalek $\mathrm{T}$, et al. The relative involvement of anterior cingulate and prefrontal cortex in attentional control depends on nature of conflict. Brain Res Cogn Brain Res 2001;12:467473.

145. Henson RN, Shallice T, Dolan RJ. Right prefrontal cortex and episodic memory retrieval: a functional MRI test of the monitoring hypothesis. Brain 1999;122:1367-1381.

146. Gehring WJ, Willoughby AR. The medial frontal cortex and the rapid processing of monetary gains and losses. Science 2002;295:2279-2282.

147. Sanfey AG, Rilling JK, Aronson JA, Nystrom LE, Cohen JD. The neural basis of economic decision-making in the Ultimatum Game. Science 2003;300:1755-1758.

148. Mulert C, Seifert C, Leicht G, Kirsch V, Ertl M, Karch S, et al. Single-trial coupling of EEG and fMRI reveals the involvement of early anterior cingulate cortex activation in effortful decision making. Neuroimage 2008;42:158-168.

149. Rigoni D, Polezzi D, Rumiati R, Guarino R, Sartori G. When people matter more than money: an ERPS study. Brain Res Bull 2010;81:445-452.

150. Etkin A, Egner T, Kalisch R. Emotional processing in anterior cingulate and medial prefrontal cortex. Trends Cogn Sci 2011;15:85-93. 
151. Coles MG. Cardiac and respiratory activity during visual search. J Exp Psychol 1972;96:371-379.

152. Porges SW, Raskin DC. Respiratory and heart rate components of attention. J Exp Psychol 1969;81:497-503.

153. Porges SW, Humphrey MM. Cardiac and respiratory responses during visual search in nonretarded children and retarded adolescents. Am J Ment Defic 1977;82:162-169.

154. Porges SW, Arnold WR, Forbes EJ. Heart rate variability: an index of attentional responsivity in human newborns. Dev Psychol 1973;8:85-92.

155. Porges SW, Stamps LE, Walter GF. Heart rate variability and newborn heart rate responses to illumination changes. Dev Psychol 1974;10:507-513.

156. Hansen $\mathrm{AL}$, Johnsen $\mathrm{BH}$, Thayer JF. Vagal influence on working memory and attention. Int I Psychophysiol 2003;48: 263-274.

157. Thayer JF, Lane RD. A model of neurovisceral integration in emotion regulation and dysregulation. J Affect Disord 2000; 61:201-216

158. Hansen $\mathrm{AL}$, Johnsen $\mathrm{BH}$, Thayer JF. Relationship between heart rate variability and cognitive function during threat of shock. Anxiety Stress Coping 2009;22:77-89.

159. Johnsen BH, Thayer JF, Laberg JC, Wormnes B, Raadal M, Skaret E, et al. Attentional and physiological characteristics of patients with dental anxiety. J Anxiety Disord 2003;17: 75-87.

160. Johnsen BH, Hansen AL, Murison R, Eid J, Thayer JF. Heart rate variability and cortiso/ responses during attentional and working memory tasks in naval cadets. Int Marit Health 2012:63:181-187.

161. Britton A, Singh-Manoux A, Hnatkova K, Malik M, Marmot MG, Shipley M. The association between heart rate variability and cognitive impairment in middle-aged men and women. Neuroepidemiology. 2008;31(2):115-21.
162. Jennings JR, Allen B, Gianaros PJ, Thayer JF, Manuck SB. Focusing neurovisceral integration: cognition, heart rate variability, and cerebral blood flow. Psychophysiology 2015; 52:214-224.

163. Duschek S, Muckenthaler M, Werner N, del Paso GA. Relationships between features of autonomic cardiovascular control and cognitive performance. Biol Psychol 2009;81: 110-117.

164. Kimhy D, Crowley OV, McKinley PS, Burg MM, Lachman ME, Tun PA, et al. The association of cardiac vagal control and executive functioning--findings from the MIDUS study. J Psychiatr Res 2013;47:628-635.

165. Mann SL, Selby EA, Bates ME, Contrada RJ. Integrating affective and cognitive correlates of heart rate variability: a structural equation modeling approach. Int I Psychophysiol 2015; 98:76-86.

166. Sandrone G, Mortara A, Torzillo D, La Rovere MT, Malliani A, Lombardi F. Effects of beta blockers (atenolol or metoprolol) on heart rate variability after acute myocardial infarction. Am J Cardiol 1994;74:340-345.

167. Stein PK, Ehsani AA, Domitrovich PP, Kleiger RE, Rottman $\mathrm{JN}$. Effect of exercise training on heart rate variability in healthy older adults. Am Heart J 1999;138:567-576.

168. Luft CD, Takase E, Darby D. Heart rate variability and cognitive function: effects of physical effort. Biol Psychol 2009;82. 164-168.

169. Luque-Casado A, Zabala M, Morales E, Mateo-March M, Sanabria D. Cognitive performance and heart rate variability: the influence of fitness level. PLoS One 2013;8:e56935.

170. Hansen AL, Johnsen BH, Sollers JJ 3rd, Stenvik K, Thayer JF. Heart rate variability and its relation to prefrontal cognitive function: the effects of training and detraining. Eur I App/ Physiol 2004;93:263-272. 